\title{
A Ruptured Large Pseudoaneurysm of the Left Ventricle
}

\author{
Junya Tanabe, Yusuke Morita, Takeshi Ouchi and Kazuaki Tanabe
}

Key words: myocardial infarction, pseudoaneurysm

(Intern Med 59: 3105-3106, 2020)

(DOI: 10.2169/internalmedicine.5227-20)
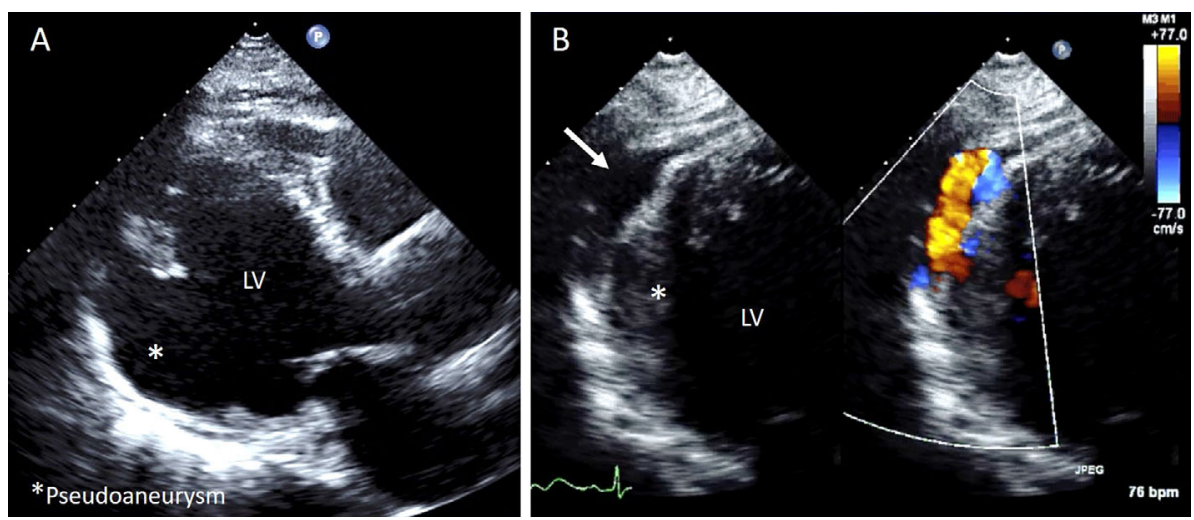

Picture 1.

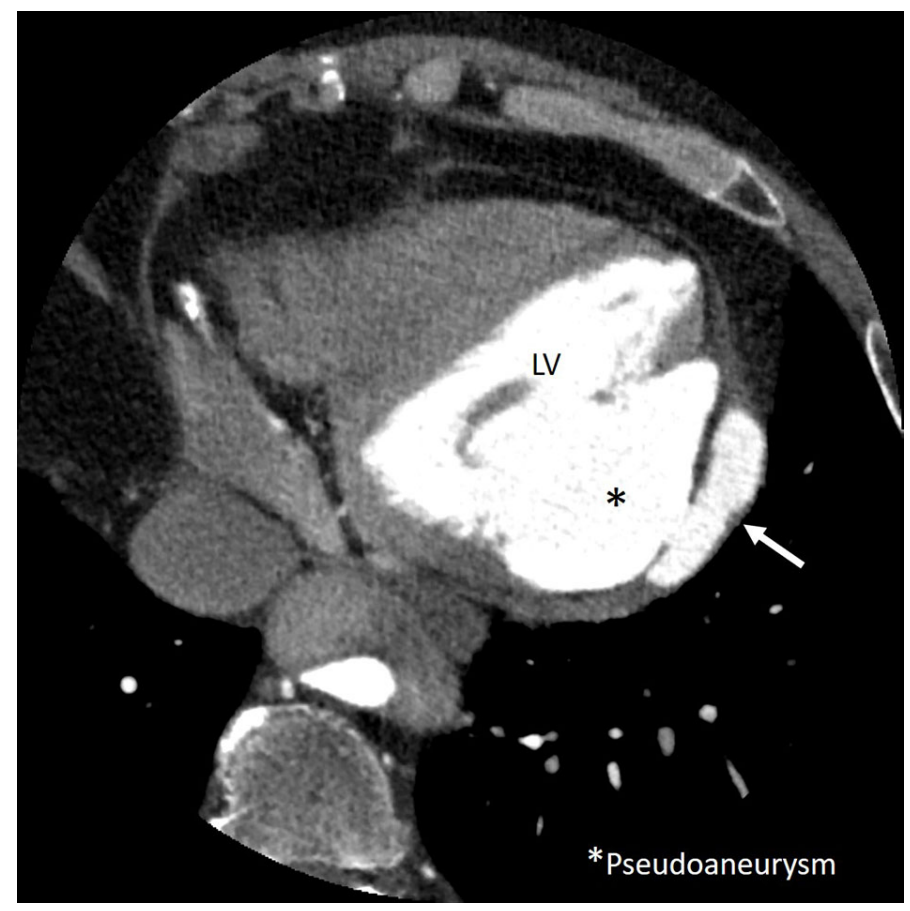

Picture 2. 


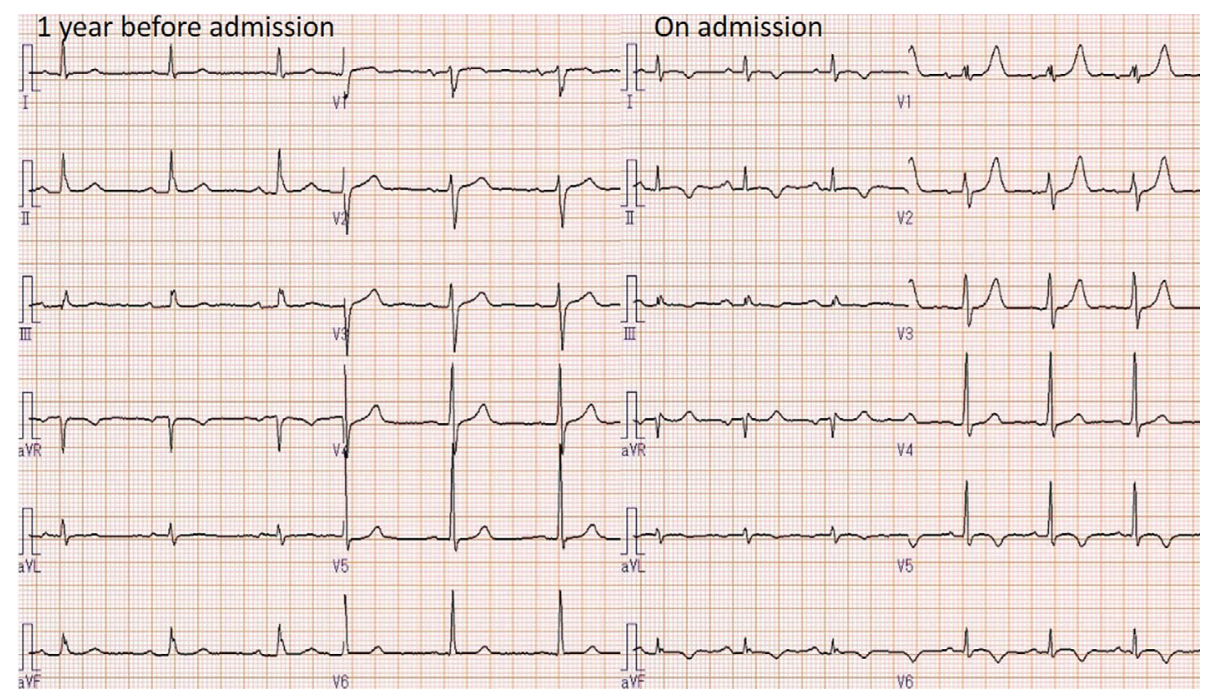

Picture 3.

A 66-year-old man presented with exertional dyspnea. One year earlier, he had underwent aortic graft replacement for Stanford type A aortic dissection and pericardial drainage for postoperative cardiac tamponade. On admission, transthoracic echocardiography (TTE) revealed a large pseudoaneurysm in the left ventricular (LV) postero-lateral wall and also the presence of a large $(45 \mathrm{~mm})$ defect (Picture 1A). A color Doppler image showed shunt flows passing from the pseudoaneurysm to the pericardial space (Picture $1 \mathrm{~B}$, arrow). The findings of contrast-enhanced computed tomography were consistent with those of TTE (Picture 2, arrow). 12-lead electrocardiography revealed an increased $\mathrm{R}$ wave in lead $\mathrm{V} 1$ and negative $\mathrm{T}$ waves in the infero-lateral leads (Picture 3). The patient was diagnosed to have a ruptured large pseudoaneurysm of the LV which was complicated with a silent myocardial infarction, and emergency left ventriculoplasty was therefore performed. Pericar- dial adhesions between the LV free wall and pericardium may have prevented a fatal rupture of the large LV pseudoaneurysm $(1,2)$.

\section{The authors state that they have no Conflict of Interest (COI).}

\section{References}

1. Frances C, Romero A, Grady D. Left ventricular pseudoaneurysm. J Am Coll Cardiol 32: 557-561, 1998.

2. Epstein J, Hutchins G. Subepicardial aneurysms: a rare complication of myocardial infarction. Am J Med 75: 639-644, 1983.

The Internal Medicine is an Open Access journal distributed under the Creative Commons Attribution-NonCommercial-NoDerivatives 4.0 International License. To view the details of this license, please visit (https://creativecommons.org/licenses/ by-nc-nd/4.0/).

(C) 2020 The Japanese Society of Internal Medicine Intern Med 59: 3105-3106, 2020 